\title{
PALABRAS EN LA INAUGURACIÓN DE LA MESA REDONDA SOBRE EL ESTADO ACTUAL DE LAS INVESTIGACIONES DEL ARTE EN MÉXICO
}

\author{
Por Jorge Alberto Manrique
}

Sr. Rector de la Universidad

Sr. Director del INAH

Señores

Hace cuarenta años que en el seno de la Universidad inició sus trabajos el Instituto de Investigaciones Estéticas, surgido por el empeño especial y decidido de don Manuel Toussaint (cuya viuda, doña Margarita Latapi de Toussaint, nos hace el honor de acompañarnos hoy), y de otros ilustres historiadores: don Rafael García Granados, don Luis Mac Gregor, don Federico Gómez de Orozco. La fundación del Instituto significaba para México y para toda la América Latina el primer intento por institucionalizar y dar formalidad académica a los estudios sobre arte. Antes de eso tal tipo de estudios no había podido ser sino la obra individual, aislada y carente de apoyo de algunos hombres esforzados, entre los cuales los propios fundadores, que por eso vieron la necesidad de establecer un "Laboratorio de Arte" -ése fue su primer nombre- que diera cuenta y razón de nuestro pasado y presente artístico, en forma coherente y sistemática, y que propiciara la reflexión consciente sobre él.

Por una circunstancia feliz, aunque no casual, don Manuel Toussaint, el fundador, reunía una serie de cualidades que hacian de él un hombre especialmente propicio para la tarea de organizar y dirigir un centro de investigación como éste. Don Manuel tenfa una muy sólida formación literaria e histórica, que se correspondía con las de otros ilustres contemporáneos suyos, o mayores, entre los que cabría citar, a guisa de ejemplo, a Luis González Obregón y a Alfonso Reyes. Con esas armas habia incursionado en las letras, en la historia, y -con una seriedad y solidez no conocidas en nuestro medio hasta entonces- en la historia del arte. Es universalmente reconocida su calidad de padre de los estudios sistemáticos sobre el arte colonial en nuestro país, pero hay que recordar también que desde muy temprano - tan pronto como 1917- había mostrado interés y dedicación por su arte contemporáneo, escribiendo sobre Saturnino Herrán. Más lejos de su personal quehacer, pero no de su preocupación, estaba el arte prehispánico, que aparece en los primeros 
planes de trabajo del naciente Instituto. La vasta curiosidad intelectual de Manuel Toussaint, la calidad de sus estudios, sobrebordada por la excelencia de una pluma que brillaba con luz propia en un medio y un momento en que escribir bien no era todavía - ni con mucho- una rareza, le habían valido un sólido prestigio, no sólo en el ambiente intelectual nuestro, sino más allá de las fronteras mexicanas. Prestigio que a menudo florecia en amistad, gracias a la afabilidad de su carácter -según testimonio de quienes de cerca lo trataron. Amistad respetuosa, académica, como la de John Mac Andrew o Diego Angulo; amistad entrañable, de hermano, como la que correspondía con Alfonso Reyes, o amistad paternal, como la que profesaría a sus discipulos.

Las prendas académicas y personales de Manuel Toussaint hacian de él una persona inmejorable para guiar aquel "Laboratorio de Arte". Su conciencia de la necesidad de tal institución lo llevó a hacer cuidadosos planes sobre el sentido de crearla y sus posibilidades de trabajo. Su prestigio obró en el ánimo del rector Fernando Ocaranza, que sintió la conveniencia de que la Universidad tomara a su cargo la tarea de examinar nuestro acervo artístico, entendiendo que tal empresa no era ni un lujo ni un adorno al lado de otras actividades universitarias, sino una necesidad verdadera para la conciencia propia del país. Expidió, pues, el 31 de enero de 1935, el acuerdo de que se fundara el "Laboratorio de Arte".

Modestos principios: un cuarto en el venerable Colegio de San Ildefonso; tres investigadores, una secretaria (aunque los tiempos han cambiado, la proporción del gasto universitario dedicada al Instituto no ha variado seguramente). Cada quien y desde luego Manuel Toussaint, aportó al laboratorio sus trabajos en proceso, sus ficheros, sus colecciones de fotografias. Le favorecía la buena relación de sus miembros: el Laboratorio de Arte de Sevilla, donde trabajaba Diego Angulo, fue su virtual padrino. A su vez el nuestro apadrinaría la creación del Instituto de Arte Americano que fundara Buschiazzo en Buenos Aires, cuya reciente desaparición, entre un jaloneo político y otro, deploramos muy deveras.

El nuestro no estuvo lejos de sufrir un percance a poco de haber nacido: cuando ocupó la rectoría Luis Chico Goerne el Laboratorio de Arte quedó subunido en 1936 a un Instituto de Investigaciones Estéticas de abultada nómina, donde tuvieron acomodo muchos personajes, después brillantes, ya en las letras, ya en actividades políticas. La cafda de Chico Goerne propició la desaparición total del Instituto. Manuel Toussaint, Federico Gómez de Orozco y Justino Fernández intercedieron 
por él, y salvaron su existencia dentro de la estructura de la Universidad, ofreciendo no cobrar sueldo y mantener de su bolsillo el estipendio de la secretaria, cosa que cumplieron hasta que la situación se normalizó.

Referirme a este serio incidente no tiene sólo el objeto de relatar una anécdota curiosa, ni sólo el de rendir tributo a la heroica actitud de los fundadores, que por esto merecen además el título de restauradores. Traerlo a cuento tiene para mí el sentido de insistir sobre la cualidad de permanencia y continuidad del Instituto. En efecto, a partir de esa tormenta, nuestro cuerpo es de aquellos que han mostrado la solidez de la Universidad como institución, aun en los momentos más críticos y difíciles, cuando los más optimistas parecen dudar de ella. Su labor ha sido continua y podemos decir que inalterable.

El plan coherente y consciente que formuló Manuel Toussaint para el primer Laboratorio de Arte, después Instituto de Investigaciones Estéticas, puede dividirse en tres puntos principales: los estudios sobre arte, con profundidad y sistemáticamente elaborados; la difusión de las investigaciones; la defensa del patrimonio artístico nacional. Como la Trinidad, esas tres finalidades -o personas- se resuelven en una sola, verdadera: crear conciencia del valor de nuestro arte pasado y presente.

Creo que a cuarenta años de distancia es posible decir que, aun con limitaciones y yerros, el Instituto ha cumplido esas finalidades y que su fundador podría verlo ahora satisfecho. Y no me parecería que fuera el caso de que se me recordara que "alabanza en boca propia es vituperio" porque me estoy refiriendo muy principalmente a la obra de quienes nos precedieron, no sólo a mí, actual director, sino a la generación de mis compañeros.

No es $t$ ! caso relatar aquí en pormenor lo que el Instituto ha realizado en cada uno de los renglones expuestos: las investigaciones primarias y variadas, publicadas como volúmenes de sus colecciones o como artículos en su revista Anales; los tres monumentales volúmenes que reúnen el resultado de esas investigaciones en su momento, de Toscano, Toussaint y Justino Fernández; piedra miliar para los estudios subsiguientes; ni la batalla diaria e ineluctable en defensa de nuestro acervo artístico. Baste señalar mi convicción de que todo eso, junto, hace de su labor un elemento central en la conciencia actual que el pais tiene de sus valores artísticos.

Esto solo, a mi modo de ver, justifica que celebremos jubilosamente el cuadragésimo aniversario del Instituto de Investigaciones Estéticas. 
Cuando la idea de tal celebración se presentó, hace meses, su entonces directora, la doctora Clementina Díaz y de Ovando, sugirió -y fue seguida sin reserva por los otros miembros del Instituto- que el recordatorio festivo no fuera únicamente un acto o varios actos sociales, más o menos serios, sino que se convirtiera en actividades académicas redituables. Asi surgió la idea de esta mesa redonda nacional y del próximo coloquio internacional que debe celebrarse en Zacatecas, en agosto. Meses más tarde, a propuesta de la doctora Beatriz de la Fuente, el Colegio de Investigadores acordó unánimemente nombrar a la doctora Díaz y de Ovando presidenta, tanto de la mesa como del coloquio, en mérito a que es hoy por hoy la decana del Instituto, a que la idea de las celebraciones había sido suya y a que bajo su gestión como directora se había iniciado la organización de ambos eventos; y-también hay que decirlo- por la indudable e inevitable simpatía que tiene entre los miembros del Colegio de Investigadores.

El título y tema de la mesa redonda que hoy inauguramos es el de "Estado Actual de las Investigaciones sobre el Arte en México". La idea rectora, pues, es la de hacer un balance, a partir de las ponencias que se presenten, y de los comentarios sobre ellas, de la situación que guardan las investigaciones artísticas. Balance que por sí mismo se justifica, puesto que nunca se ha hecho uno -salvo intentos personales aislados--, y que tiene además la ventaja particular de que, siendo organizado el evento por nuestro Instituto, nos permitirá tomar conciencia de faltas, fallas, yerros que el Instituto esté en posibilidad de atender.

Puesto que, como he dicho, creo que el Instituto ha sido piedra fundamental en tales estudios -y me parece no mentir si digo que esa opinión es compartida por mis colegas-, el que nosotros mismos fuéramos ponentes traería dos inconvenientes: podria caer en el elogio propio, y no daría tal vez espacio suficiente a puntos de vista ajenos a este cuerpo, que (dicho entre paréntesis) son los que más nos interesan ahora. De tal modo que se pensó que todos los ponentes debían ser externos. Para evitar algo que todos hemos sufrido con frecuencia en los congresos a que los inescrutables caminos de la providencia nos han llevado, es a saber, la falta de estructura y la disparidad de las intervenciones, se formuló una comisión, constituida por la doctora Beatriz de la Fuente, la doctora Elisa Vargas Lugo, y el maestro Xavier Moyssén, para discutir la manera más adecuada de estructurar las aportaciones y las personas más idóneas que podrían ser invitadas. Se dividió el trabajo, muy clásicamente, en arte prehispánico, arte colonial y arte moderno y contempo- 
ráneo, y cada uno de los investigadores citados es coordinador, respectivamente, de cada una de esas partes. Sobre la idoneidad de los ponentes invitados juzgará el público, en este caso activo, puesto que se ha planteado toda la mesa redonda sobre la idea de un público participante, que esperamos intervenga tanto cuanto el tiempo lo permita y aporte luces a lo que aquí se presente.

Quiero insistir en el hecho de que, en la medida de lo posible, se trató de invitar a ponentes foráneos. Deben ustedes ver en esto un esfuerzo, todavía raquítico quizá, por ligar al investigador de la rica provincia con las actividades del Instituto y, reciprocamente, por llevar la labor del Instituto a esa provincia - no sólo a sus monumentos, que siempre lo ha hecho, sino a la gente que labora sobre ellos, tantas veces sin apoyo alguno y rodeada de incomprensión. Esto, que sentimos como una necesidad vital para el Instituto y para la investigación artística en México, coincide, por cierto, con una reciente política de la Universidad que hace esfuerzos serios en ese sentido. Confesamos que esto no es sino un principio; si bien algunos historiadores nos son ampliamente conocidos, en ocasiones ignoramos hasta los nombres de quienes se dedican en otras ciudades a menesteres similares a los nuestros. Esperamos que pronto inicie el Instituto otras actividades de este tipo, de las cuales el intento presente no es sino una pequeña primicia. Se ha pedido al historiador potosino don Rafael Montejano y Aguinaga que, al cierre de la mesa redonda, haga el balance de lo que para un investigador externo signifique lo que aquí se haya tratado.

No puedo terminar estas palabras sin hacer un recuerdo doloroso, afectuoso, respetuoso, de los miembros del Instituto que han muerto durante sus cuarenta años de vida. Manuel Toussaint, Rafael García Granados, Luis Mac Gregor, Federico Gómez de Orozco, Vicente Mendoza, de ese caballero de la inteligencia que fue Manuel Romero de Terreros; de los muertos trágicamente en juventud: Salvador Toscano y Raúl Flores Guerrero; y especialmente, por lo más cercano y todavía doloroso, de don Justino Fernández, a quien con fina perspicacia hizo don Manuel Toussaint entrar en el Instituto a poco de fundado, previendo los muchos ricos frutos que llegaría a dar; él habria de ser su sucesor en la dirección del Instituto y se puede decir que configuraría para éste la imagen que ahora vemos; y don Francisco de la Maza, discipulo predilecto de don Manuel, hombre brillante en tantos quehaceres; en la cátedra, en la pluma, en la defensa fogosa de los monumentos artísticos. Los dos últimos fueron los maestros de muchos de quienes, 
con mayor o menor fortuna, trabajamos sobre historia del arte, dentro o fuera del Instituto.

Quédame agradecer, muy deveras, el apoyo moral y económico que el rector de la Universidad ha dado a la realización de este evento, y su presencia, así como la del director del Instituto Nacional de Antropología e Historia, la de la señora Toussaint y demás personas que presiden este acto; la de los directores y miembros de instituciones afines, y desde luego la de todos ustedes.

También agradezco la hospitalidad generosa que nos brinda la División de Psicología, Psiquatría y Salud Mental, en esta sala.

Como punto final permítanme decir: no nos asusta la polémica ni la crítica, queremos oírla y atenderla según nuestra propia capacidad y opinión; nos sentiríamos, en cambio, en cierta medida defraudados si tuviéramos un público complaciente y pasivo: lo cual no quiere decir que no estemos dispuestos a defender nuestro punto de vista hasta donde nos parezca razonable. Estamos en una Universidad.

Muchas gracias. 